\title{
O PAPEL DA EQUIPE MULTIDISCIPLINAR EM CURSOS TÉCNICOS A DISTÂNCIA (E-TEC/EAD/UFPB): REFLEXÕES E VIVÊNCIAS
}

\author{
JOÃO PESSOA/PB MAIO/2018
}

\author{
Marcia Sandra Meireles de Melo - UFPB - marciammelo@hotmail.com \\ Marinilson Barbosa da Silva - UFPB - professor.marinilson@gmail.com \\ Ranyieri D Avila Alves Coelho - UFPB - ranyeri@ets.ufpb.br \\ Jose Moreira da Silva Neto - UFPB - neto0000@hotmail.com \\ Tipo: Relato de Experiência Inovadora (EI) \\ Categoria: Métodos e Tecnologias \\ Setor Educacional: EDUCAÇÃo MÉDIA E TECNOLÓGICA
}

\begin{abstract}
RESUMO
O objetivo central desse artigo busca compreender do ponto de vista fenomenológico o papel e a importância da equipe multidisciplinar em cursos técnicos a distância, a partir de um relato de experiência (período de 2017-2018), tendo como contexto e exercício profissional a Escola Técnica da Saúde da Universidade Federal da Paraíba (ETS/UFPB). A Escola Técnica da Paraíba, via UFPB, no ano de 2017 foi contemplada pelo Ministério da Educação e Cultura (MEC) para oferecer cursos técnicos a distância para estudantes que estão cursando o ensino médio em escolas públicas (Programa E-Tec/MedioTec). Vários cursos técnicos estão sendo ofertados como: análises clínicas, cuidado de idosos, meio ambiente, enfermagem, guia de turismo, dentre outros. Alguns profissionais foram selecionados e dentre eles os que compõem o cenário da chamada equipe multidisciplinar, que consiste basicamente no exercício dos profissionais que atuam na função de Pedagogo, Psicólogo e o Assistente Social. Nesse sentido, a partir de um relato fenomenológico existencial o artigo busca refletir sobre os dilemas, limites e possibilidades dos profissionais que fazem partes desse universo.
\end{abstract}

Palavras-chave: Equipe Multidisciplinar. Fenomenologia. Cursos Técnicos em EAD. 


\section{INTRODUÇÃo}

O propósito inicial desse artigo busca compreender do ponto de vista fenomenológico sobre o papel e importância da equipe multidisciplinar em cursos técnicos a distância (EAD/E-Tec/UFPB).

A Rede e-Tec Brasil embasada pela Lei de Diretrizes e Bases da Educação Nacional (LDB) no 9.394/96, na Educação Profissional e Tecnológica, originou-se pelo Decreto no 6.301/2007 que a criou como Sistema Escola Técnica Aberta do Brasil, e a partir do Decreto $n^{\circ} 7.589$, de 26 de outubro de 2011, ficando assim instituída como Rede e-Tec Brasil, tendo a finalidade de desenvolver a Educação Profissional e Tecnológica na modalidade de Educação a Distância (EaD). Sua proposta constitui-se em uma das ações do Plano de Desenvolvimento da Educação no âmbito da política de expansão da educação profissionalizante do Ministério da Educação. Sendo a rede uma das ações que integram o Programa Nacional de Acesso ao Ensino Técnico e Emprego (Pronatec), assim além das Instituições Públicas de Ensino Federais e Estaduais, integram a Rede eTec Brasil os Serviços Nacionais de Aprendizagem que ofertam cursos de educação profissional e tecnológica. Nesse sentido, O E-Tec é uma extensão da Secretaria de Educação Profissional e Tecnológica (SETEC) do Ministério da Educação e vem somando esforços em torno da construção e consolidação de um sistema que contribua para ampliação de vagas na educação técnica e profissional também por meio da Educação a Distância.

Lançado em 2007, o sistema Rede E-Tec Brasil visa à oferta de educação profissional e tecnológica a distância e tem o propósito de ampliar e democratizar o acesso a cursos técnicos de nível médio, públicos e gratuitos, em regime de colaboração entre União, Estados, Distrito Federal, Municípios e Universidades Federais. Os cursos serão ministrados por instituições públicas (BRASIL, 2016, p.12-14).

A Escola Técnica da Paraíba, através da Universidade Federal da Paraíba (UFPB), no ano de 2017, foi contemplada pelo Ministério da Educação e Cultura (MEC) para oferecer cursos técnicos a distância para estudantes que estão cursando o ensino médio em escolas públicas (Programa E-Tec/MedioTec). Vários cursos técnicos estão sendo ofertados como: análises clínicas, cuidados de idosos, meio ambiente, enfermagem, guia de turismo, dentre outros. Dentro desse cenário tecnológico, alguns profissionais foram selecionados e dentre eles os que compõem o universo da chamada equipe multidisciplinar, que consiste basicamente no exercício dos profissionais que atuam na função de Pedagogo, Psicólogo e o Assistente Social. São esses profissionais que acabam sendo responsáveis pela dinamização dos aspectos interpessoais como parte 
dos processos de ensino-aprendizagem e gestão de pessoas, diante dos elementos tecnológicos existentes em cursos de EAD.

\section{EDUCAÇÃO A DISTÂNCIA, EQUIPE MULTIDISCIPLINAR E O AVANÇO DAS TECNOLOGIAS DA INFORMAÇÃO E COMUNICAÇÃO (TICs)}

Nos dias atuais a Educação a Distância (EAD) cresce em ritmo acelerado motivado pelas possibilidades decorrentes das Novas Tecnologias da Informação e Comunicação (TICs) e por sua inserção em todos os processos produtivos e educacionais. Cada vez mais cidadãos e instituições veem nessa forma de educação um meio de democratizar o acesso ao conhecimento, bem como de propagar oportunidades de trabalho e aprendizagem durante o processo de vida. É fato que cada vez mais a procura por cursos ofertados pela Educação a Distância cresce, alavancada pelos avanços tecnológicos e pela facilidade de o aluno gerenciar seu próprio tempo e ritmo de aprendizagem.

Segundo Castells (2002, p.38), "as Tecnologias da Informação e da Comunicação estão integrando o mundo em redes globais de instrumentalidade. Como revolução tecnológica, as TICs começam a remodelar a base material da sociedade em ritmo acelerado". A comunicação mediada por computadores gera uma gama enorme de comunidades virtuais e cursos a distância.

O avanço tecnológico trouxe novas perspectivas para a educação a distância, aumentando os espaços e os tempos para a socialização do conhecimento. As possibilidades de interação estruturadas pelas tecnologias da informação e da comunicação vêm contribuindo para superar antigos preconceitos em relação à $E A D, e$ agora têm dado lugar a um consenso em torno da ideia de que a EAD desempenha um papel cada vez mais decisivo na definição dos modernos ambientes de aprendizagem.

O E-tec/UFPB apresenta na sua estrutura administrativa uma equipe multidisciplinar que atende as diferentes necessidades dos alunos, mediadores e professores formadores. As necessidades dos cursos e de todos os sujeitos envolvidos são amplas e complexas, portanto, diante de todo o aparato tecnológico, determinados problemas técnicos e existenciais são apontados por Luzzi e Luswarghi (2006), tais como a falta de atualização dos profissionais envolvidos em EAD e a escassa comunicação promovida entre os alunos, mediadores, coordenadores e professores formadores, que geram isolamento e empobrecimento no trato da informação e comunicação; falta de motivação e evasão dos alunos e limitação do potencial de transferência dos conhecimentos à prática, a outras realidades ou problemas. Diante disso cabe ressaltar que as práticas 
pedagógicas exercidas em cursos a distância mediadas pelas TICs, estão intimamente interligadas a determinados conceitos e modelos de educação a distância; nas diferentes ações e instâncias que fazem parte do universo da EAD, como ser aluno, professor, coordenador, mediador e também dos componentes que fazem parte da equipe multidisciplinar. Nesse sentido, encontram-se subjacentes conceitos e modelos educativos, fundamentados em determinadas teorias do conhecimento, ou seja, os diferentes "modelos" emergem de referenciais teóricos e pedagógicos que vêm dando sustentação às práticas e ações pedagógicas e administrativas no campo da Educação a Distância nesses últimos tempos.

\subsection{O PAPEL DA EQUIPE MULTIDISCIPLINAR NO CONTEXTO DA ESCOLA TÉCNICA DA SAÚDE (ETS/UFPB)}

Conforme o Regimento Interno da Escola Técnica da Saúde, da Universidade Federal da Paraíba (UFPB), o papel e as funções dos membros que compõem a equipe multidisciplinar são:

\section{- Pedagogo}

Acompanhar as atividades e a frequência dos alunos, atuando em conjunto com os demais profissionais para prevenir a evasão e aplicar estratégias que favoreçam a permanência;

Articular as ações de acompanhamento pedagógico relacionadas ao acesso, à permanência, ao êxito e à inserção sócio-profissional;

Promover atividades de sensibilização e integração entre os alunos e equipes do programa;

Acompanhar o desenvolvimento e cumprimento do estabelecido no Projeto Pedagógico dos Cursos.

\section{- Psicólogo}

Atuar em parceria com a equipe multidisciplinar (Pedagoga e Assistente Social) e equipe diretiva nos processos de articulações, planejamentos e intervenções frente às demandas que perpassam o cotidiano escolar no contexto do E-Tec;

Promover palestras nos polos e/ou webconferências, via ambiente moodle ou 
presencialmente, sobre "evasão escolar", "preparação para o ingresso no mundo do trabalho", "Múltiplas Inteligências", dentre outras;

Desenvolver e disponibilizar um trabalho de "escuta psicológica e de intervenção" entre os alunos que apresentem algum tipo de necessidade específica, que poderão ser agendados nos horários disponíveis pelo psicólogo;

Participar de reuniões de planejamento com a equipe multidisciplinar e coordenações;

Realizar, quando necessário, o aconselhamento e acompanhamento sistematizado dos alunos buscando auxiliá-los nas dificuldades e nos problemas psicossociais vivenciados.

\section{- Assistente Social}

Promover mecanismos de acompanhamento e intervenção no processo de ensino e aprendizagem contribuindo no combate à evasão junto à equipe multidisciplinar;

Gerenciamento dos Auxílios Estudantis junto aos Professores Mediadores e Coordenadores de Curso;

Acompanhar e orientar os discentes a respeito dos processos de auxílios estudantis e sobre o funcionamento do programa;

Oferecer feedback à Coordenação Geral do Programa sobre o acompanhamento realizado nos Polos.

A constituição do perfil e do papel de cada membro da equipe multidisciplinar é um empreendimento complexo, não é obra de um dia, requer um trabalho interativo entre todos. É necessário ficar atento, pois existe o perigo de traçar um perfil tão perfeito que seja irrealizável ou que pareça tão irrealizável aos profissionais da área que eles desistam no primeiro momento.

De acordo com os Referenciais de Qualidade na EAD do MEC (BRASIL, 2007, P.19), o mesmo afirma:

Em educação a distância, há uma diversidade de modelos, que resulta em possibilidades diferenciadas de composição dos recursos humanos necessários à estruturação e funcionamento de cursos nessa modalidade. Os recursos humanos devem configurar uma equipe multidisciplinar com funções de planejamento, implementação e gestão de cursos à distância a qual deve estar composta por três categorias de profissionais: docentes, tutores e profissionais técnico-administrativo nas dimensões administrativas como nas tecnológicas. 
Dessa maneira, esse documento traz ainda algumas contribuições no sentido de relatar que as instituições que oferecem cursos a distância, além dos docentes que elaboram as disciplinas e dos tutores, devem dispor de profissionais capazes de estabelecer os fundamentos teóricos do projeto. Esses profissionais têm a função de selecionar e preparar todo o conteúdo curricular do curso, articulado a procedimentos e atividades pedagógicas, como motivar, orientar, acompanhar e avaliar os aluno.

O desenvolvimento de programas e projetos na modalidade a distância é um processo que exige um planejamento detalhado e por isso requer a formação de equipes multiprofissionais comprometidas tanto com a parte tecnológica quanto com a parte pedagógica. Além disso, é importante que esses profissionais estejam inteirados sobre a proposta do curso. Conforme Behar e Cols. (2009, p. 126 e 127),

\footnotetext{
para que um grupo possa colocar seu objetivo comum em prática, é necessário que os sujeitos compreendam o ponto de vista do outro e, mesmo que não concordem, argumentem e articulem as diferentes contribuições, construindo-as em um novo patamar. Dentro disso, as funções individuais e coletivas alimentam-se mutuamente em prol de uma lógica comum e de um pensamento equilibrado, não podendo ser entendidos como uma relação dicotômica.
}

Partindo desse princípio, tanto no desenvolvimento quanto na prática aplicada em cursos a distância, o sentido de equipe é um ponto crucial. O trabalho colaborativo entre as partes envolvidas poderá se concretizar em um produto de qualidade. $O$ conhecimento e a interação dessas pessoas irão favorecer o sucesso ou o fracasso do programa, uma vez que está nelas a responsabilidade de acompanhar a dinâmica dos cursos, a interatividade e a permanência dos alunos.

\section{PROCEDIMENTOS METODOLOGICOS}

A opção teórico-metodológica adotada nesse artigo é a perspectiva fenomenológica. A Fenomenologia vem-se constituindo em um dos principais referenciais teóricometodológico na trajetória investigativa das ciências humanas e consequentemente na área da Educação. Sua influência não está restrita à Filosofia, mas se faz presente também em diferentes áreas do conhecimento. Neste sentido, tanto como abordagem teórica, quanto como método de investigação, a Fenomenologia caracteriza-se como um esforço de retorno à experiência, à vida, ao mundo da experiência, ao mundo vivido e "circundante", como base do processo de construção do conhecimento. "Este desvelamento gradual e progressivo de novas camadas veladas constitui o círculo hermenêutico" (MORAES, 1991, p.21).

Para Forghieri (2004), o "mundo circundante" é o conjunto de relações significativas 
dentro do qual a pessoa existe.

O "mundo circundante" se estabelece por via do relacionamento da pessoa com o que se costuma denominar de ambiente. O mundo circundante abrange os condicionamentos aos quais se está sujeito por se viver concretamente num ambiente determinado. No entanto, embora em sua vida sofra limitações e necessite adaptar-se a seu ambiente, o ser humano possui também a capacidade de transcendê-lo por meio da consciência das situações que vivencia. Ele não está em seu mundo circundante como um objeto dentro de uma caixa ou um animal preso numa jaula; não está, simplesmente, restrito a um ambiente. Mora ou habita no e o mundo, que para ele se abre com muitas possibilidades, não apenas por poder se locomover de um lado para outro, mas também em virtude da consciência que possui das situações que já vivenciou, está vivenciando e ainda poderá vivenciar. Há, portanto, uma relação, um movimento dialético entre o ser humano e o mundo circundante.

Neste sentido, a perspectiva fenomenológica amplia a dimensão da educação a distância como sendo parte de um fenômeno transacional (interpessoal) essencialmente humano e pedagógico presente nas relações desse indivíduo com os outros mediatizados pelas tecnologias. O encontro entre o papel e as funções da equipe multidisciplinar com a Fenomenologia acaba redimensionando assim a percepção do ato de educar e de gerir no contexto da EAD. $O$ ato de educar e gerir na perspectiva fenomenológica resgata a dimensão da experiência do vivido, da presença do outro, da intencionalidade como construção de significados e da importância dos sentimentos e percepções desses diferentes sujeitos que compõem o universo da EAD. Em relação a essas dimensões apontadas, Heidegger, utiliza o conceito de "temporalidade da compreensão", entendido como um processo de apreensão do modo existencial de compreensão de si e do outro, ou seja, como "o ser projetando-se num pode ser, em função do qual a presença sempre existe. A compreensão abre o 'poder-ser' próprio de tal maneira que compreendendo a presença, de algum modo, sempre se sabe a quantas ela anda consigo mesma" (HEIDEGGER, 2005, p. 132).

\section{APRESENTAÇÃO E DISCUSSÃO DOS RESULTADOS}

A equipe multidisciplinar do E-tec/UFPB faz um trabalho coletivo, político e pedagógico dos cursos, considerando sempre o aluno como foco do programa e o principal pilar para garantir a qualidade do curso. É imprescindível deixar claro que a educação se faz com e para pessoas. Por trás de plataformas virtuais, de material didático e outras tecnologias, existem competências, habilidades de profissionais comprometidos com a qualidade do ensino e aprendizagem dos cursos ofertados pelo programa. 
A equipe multidisciplinar além de estimular a interação aluno, mediador, professor, como também entre colegas de curso, é responsável por contribuir para evitar a evasão e manter um processo significativo e motivador de aprendizagem, possibilitando a exploração das mais diversas ferramentas, recursos e mídias digitais que incentivem à interatividade e a autonomia para monitorar o próprio desenvolvimento do aluno. Os cursos a distância precisam estar estruturados com uma equipe de recursos humanos adequadas para promover o desenvolvimento e o bom funcionamento do mesmo.

Desenhamos os caminhos a percorrer pelo e-Tec na UFPB, mas para onde estamos a caminhar? Quais as possibilidades e desafios? Podemos também apontar não princípios, mas estratégias, ações que podem ser seguidas para que cheguemos ao caminho desejado e que realizamos com frequência, tais como: facilitar o uso didático e pedagógico das tecnologias, proporcionar formação continuada, reuniões, palestras motivacionais com todos os agentes envolvidos, avaliar o caminho percorrido, realizando visitas in loco nos Polos, e como destaque tivemos o Primeiro Encontro de Ensino Técnico a Distância da Escola Técnica da Saúde (ETS) da Universidade Federal da Paraíba (UFPB), ocorrido na cidade de Bananeiras - PB, apresentou como temática central: "Desafios e Possibilidades Frente às Demandas da Rede E-TEC no Contexto da UFPB", tendo a Equipe Multidisciplinar como parte da comissão organizadora do evento, foi um momento marcante para todos os sujeitos envolvidos na dinâmica do ETec. Os objetivos centrais do evento consistiram, justamente, no ato e importância de se refletir coletivamente sobre os processos e dinâmicas de construção e implementação dos cursos técnicos a distância que estão sob a responsabilidade da ETS nos diferentes campi da UFPB e também proporcionar um momento de troca de experiências e integração entre os diferentes atores que fazem parte da dinâmica dos cursos técnicos. O impacto desse encontro foi notório nas falas de todos os envolvidos e de como o evento contribuiu de forma significativa sobre os sentidos e significados dos processos e inserções dos diferentes cursos no contexto da ETS/UFPB, e de forma individual da importância da integração desse sujeito/indivíduo no cenário estrutural do sistema e organização E-Tec.

\section{CONSIDERAÇÕES FINAIS}

Um primeiro ponto a ser destacado aqui é que o papel da Equipe Multidisciplinar deve se constituir como tal, buscando trabalhar em redes com os demais e diferentes setores. Outro ponto importante é que a configuração dos cursos técnicos a distância, veiculados pelo programa E-Tec ainda estão em "processos de construção". Nesse sentido, há um contexto eminente de limites e horizontes, de potencialidades e de temporalidades. As contribuições fenomenológicas são importantes no sentido de despertar nos sujeitos 
envolvidos um processo de construção de sentidos e significados individuais e coletivos, ou seja, o seu fazer e seu saber não emergem no vazio, mas em espaços macro e microssociais, fluentes em tempos históricos de curta, média e longa duração, em realidades fundadas nas dimensões materiais e simbólicas, presentes como matrizes de significação, construídas nas práticas instituídas e instituintes de sujeitos individuais e coletivos, no cotidiano de suas vidas pessoais e profissionais. Na perspectiva fenomenológica, são experiências tecidas no mundo vivido, marcadas pela temporalidade presencial ou virtual. Assim, em suas relações com um mundo circundante, um mundo humano e um mundo próprio, os membros da equipe multidisciplinar e de outros setores, vão se lapidando, apresentando entre si continuidades e descontinuidades, ajustes e reajustes, significando e ressignificando a cada dia a sua prática pessoal e coletiva no contexto da EAD.

Considerando as reflexões e vivências no E-tec/UFPB, pode-se constatar que a multidisciplinaridade é a essência e o norte de qualquer trabalho que se pretende realmente coletivo, pois, por meio dela, temos a oportunidade de fortalecer não só o senso de equipe, a coletividade, como também amplificar a afetividade, a sensibilidade, a criatividade, o companheirismo, a empatia, a solidariedade; enfim, um bem-estar essencial para qualquer tipo de atividade pedagógica, a ser desempenhada.

\section{REFERENCIAS}

BEHAR, Patrícia Alejandro e Cols. Modelos Pedagógicos em Educação a Distância. Porto Alegre: Artmed, 2009.

BRASIL, MEC. Referenciais de Qualidade para Educação Superior a Distância, Brasília: [ s.n]. 2007.

BRASIL. Manual de Gestão da Rede e-Tec Brasil e do Profuncionário. Versão Preliminar 1.2 de Abril de 2016. Brasília, DF, 2016.

CASTELLS, Manuel. Sociedade em Rede. São Paulo: Paz e Terra, Vol. I, 2002.

FORGHIERI, Yolanda Cintrão. Psicologia Fenomenológica: Fundamentos, Método e Pesquisas. São Paulo: Pioneira Thompson, 2004.

HEIDEGGER, Martin. Ser e Tempo. Petrópolis: Ed. Vozes, Parte I e II, 2005. 
Contexto Latino-Americano. Disponível em:

http://www.abed.org.br/publique/cgi/cgilua.exe/sys/start.htm?UserActiveTemplate=4abed \&infoid=142\&sid=114 Acesso em 22/02/2006.

MORAES, Roque. A Educação de Professores de Ciências: Uma Investigação da Trajetória de Profissionalização de Bons Professores. Porto Alegre, UFRGS, 1991. (Tese de Doutorado). 